\title{
Supporting the transition to online teaching through evidence-based professional development
}

\author{
Darci Taylor \\ Deakin University \\ Geelong, Australia
}

\author{
Joanne Elliott \\ Deakin University \\ Geelong, Australia
}

\begin{abstract}
Professional development (PD) is essential to support teachers to transition to online teaching, yet there are few evidence-based guidelines to assist those designing PD to determine both its content and structure. This paper provides an example of the design of an evidence-based PD resource that drew on Kilgour et al.'s (2019) threshold concepts, Northcote et al.'s (2019) pedagogical guidelines for PD and various institutional inputs as a form of evidence. By combining these sets of evidence, the resource was designed to support teachers to develop skills for online teaching that was both evidence-based, and tailored to the educational context and needs of staff. The paper adds to the literature by providing those developing PD with an example of how institutional inputs can be combined with scholarly research to develop an evidence-based PD program that was readily adaptable to support staff teaching online during the COVID-19 pandemic.
\end{abstract}

Keywords: professional development, evidence-based, online teaching, COVID-19. Introduction

Professional development (PD) support is essential for staff to successfully transition from face-to-face teaching to teaching online, yet it is not always clear what structure this PD should take nor the content that the PD should include (Northcote, Kilgour, Reynaud, Gosselin, \& McLoughlin, 2019). For example, PD for online teaching may be structured as general or tailored workshops, a collection of just-in-time resources, at-elbow support, or communities of practice; all of which have their own benefits and challenges. Decisions also need to be made regarding the content to include in the PD; for instance, which pedagogical focus, or topics to include, such as assessment design, feedback, course design, or asynchronous online facilitation. There are few guidelines to assist those developing PD in this decision making process, leading to calls for a more "evidence- based, researchinformed approach to guide the development of PD” (Northcote et al., 2019, p. 340).

This paper contributes to this discussion by providing advice on how to design a PD resource for teachers transitioning to online teaching that is both evidence-based and contextualised to the needs of staff. It identifies the institutional 'evidence' that can be used to complement published research, thereby assisting those developing PD in design decisions.

The PD resource outlined in this paper was created as part of our institution's 'CloudFirst' project -a major curriculum innovation project that redesigned units for 'premium' online delivery (Deakin University, 2020). The resource, 'CloudFirst102' drew on four types of evidence: two from the research literature (Kilgour et al.'s (2019) threshold concepts and Northcote et al.'s (2019) pedagogical guidelines for PD); and two institutional forms of evidence that enabled the PD program to be tailored to the educational context and particular needs of our staff.

The evidence-informed design decisions made in the development of CloudFirst102, and its sister PD resource 'CloudFirst101' (described below), allowed both resources to be readily adapted and flexibly applied to support staff during the rapid transition to teaching online brought about by the COVID-19 pandemic.

\section{Background: What is CloudFirst?}

CloudFirst is a curriculum redesign project focused on prioritising students' online learning experience by creating premium online learning materials complemented by on-campus or online active \& collaborative learning (Deakin University, 2020). The collaborative redesign process takes place over approximately 22 weeks where academic staff are supported by the multidisciplinary CloudFirst Team (academics, senior educational designers and digital resourcing staff) to reimagine their units for online delivery. The learning design approach draws heavily on Laurillard's (2012) Conversational Framework and is underpinned by our institutional policy on premium learning 
and teaching, which we cluster into five CloudFirst Learning Designthemes: learning is scaffolded, learning is activity-focused, learning is feedback-focused, learning is social, and learning is supported (Elliott \& Taylor, 2019).

To support staff to conceptualise what a CloudFirst approach looks like, we* created a self-paced capability building resource 'CloudFirst101' within our existing learning management system to role-model the learning design approach and position staff as learners so that they could experience CloudFirst from a student's perspective (see Elliott \& Taylor (2019) for a description of this resource). To complement CloudFirst101, we created a subsequent capability building resource 'CloudFirst102', which was designed to support staff to develop skills in online teaching.

\section{Initial design decisions for CloudFirst102}

The aim of CloudFirst102 was to combine suggestions for practical teaching strategies contexualised to the institution with pedagogical theory as a means to illustrate good practice in online teaching. This need emerged out of our experiences of implementing the CloudFirst project, where we had concentrated heavily on the design of online learning resources, yet feedback from teaching staff indicated that there was also a need for capability building around facilitating online learning within the context of the newly designed unit sites. The new unit designs required staff to facilitate active and collaborative learning in an online, flipped-classroom model, where synchronous learning experiences complemented online asynchronous learning resources and activities. For some staff, this required a large shift in their usual teaching practice.

We encapsulated the aim of CloudFirst102 in the form of a big question, 'How can I effectively facilitate student learning in a CloudFirst unit?' that served to guide the narrative of CloudFirst102. Due to the operational demands of the CloudFirst project, CloudFirst102 was not designed to require active facilitation from the CloudFirst team, but instead was designed to be self-paced, where staff could access the resource as needed. Nonetheless, we invited staff to share stories via the embedded discussion forums within CloudFirst102 as a mechanism to keep the resource dynamic and current, and to foster peer learning in a way that didn't rely on intense educator facilitation.

To further assist in our decision making regarding the structure and content of CloudFirst102, we heeded Northcote et al.'s (2019) call for evidence-based PD and drew on varied forms of evidence; including personal experience, observation, testimony, artefacts, documents and research (Thomas, 2004). Below we outline the different forms of evidence used to underpin the design of CloudFirst102.

\section{The evidence-based framework underpinning CloudFirst102}

\section{Input 1: research evidence}

Kilgour et al.'s (2019) research identified 12 threshold concepts related to online pedagogy that novice online teachers must grasp. These cluster around the themes of preparation and course design, online presence, and interaction and relationships. Kilgour et al. notes that using threshold concepts as a way to approach PD is an emerging field in higher education. The benefits of using threshold concepts within PD is that it enables online teachers to develop confidence and competence by positioning them as a learner and enables the identification of challenges that need overcoming (Kilgour et al., 2019). We have previously successfully applied the technique of 'teacher as the learner' in CloudFirst101 where we role-modelled CloudFirst Learning Design so teachers could learn about the threshold concept theme of preparation and course design (Elliott \& Taylor, 2019). The content of CloudFirst102 was consequently informed by the latter two threshold concept themes of online presence, and interaction and relationships.

\section{Input 2: research evidence}

Building on Kilgour et al.'s (2019) idea of threshold concepts, Northcote et al. (2019) developed guidelines for the structure and content of PD programs for novice online teachers that can be applied at either an institutional or individual level. In the example at their institution, training needs were identified in areas such as online communication software and tools, assessment and feedback, structuring online and on-campus courses in an equitable and engaging manner, clarifying expectations, online presence and constructive alignment. Northcote et al. points out that the structure of PD interventions need to be customised to local needs through localised research. We conducted this localised research by undertaking a scan of existing PD offerings at our institution which indicated that some of the topics suggested by Northcote et al. were already well supported and hence we decided not to duplicate them in CloudFirst102, instead we referred staff to these where needed. We further contextualised 
Northcote et al.'s recommendations to our local needs through additional forms of evidence that formed the basis for inputs 3 and 4 .

\section{Input 3: institutional evidence (personal experience, testimony, artefacts \& research)}

To ensure the content of CloudFirst102 was relevant to staff needs, we also drew on institutional evidence collected over the evolution of the CloudFirst project. Much of this evidence took the form of personal experiences and testimonies, or 'craft knowledge' (Thomas, 2004) that we combined with research evidence to provide learners with contextualised good-practice examples they could incorporate into their teaching practice.

The institutional evidence we drew on included:

- personal experiences from project stakeholders reflecting key challenges staff faced when moving online

- findings from internal evaluations (incorporating both student and staff personal experiences)

- student testimonies about their experiences over the trimester journey gained through user experience research, and reflective contributions from a student pedagogical consultant who worked with the CloudFirst Team as part of a 'students as partners' internship

- staff testimonies captured through embedded discussions where learners could share their experiences and reflections on teaching (eg. craft knowledge)

- exemplars of practical teaching strategies (testimonies) and online learning materials (artefacts) developed throughout the CloudFirst project

- published research from our colleagues and/or research undertaken at our institution, and

- colleagues' testimonies captured through video, audio and text that described their experience of teaching online across the trimester journey.

We specifically captured colleague's testimonies aligned to Kilgour et al.'s (2019) threshold concepts as this provided learners with a range of perspectives on how these concepts were approached. By providing these insights we hoped to assist learners in grasping these concepts for themselves and overcome some of the liminality, uncertainty and anxiety associated with mastering threshold concepts (Meyer \& Land, 2005). By sharing these stories, we aimed to model good practice, provide examples of 'how to' (Kilgour et al., 2019), and inspire staff to think about how to master threshold concepts themselves. For example, the threshold concept of "Online teaching requires facilitating interaction, not only presenting content" (Kilgour et al., p. 1427) was illustrated through a podcast testimonial where an academic teaching staff member described how she proactively fostered social connections between first-year students by designing more opportunities for groupwork in online seminars and facilitated asynchronous discussion forums on current/topical issues.

We focused on showcasing exemplars and suggesting practical online teaching alternatives, rather than focusing on technologies, as a way to encourage the transformation of teaching (Kilgour et al., 2019). So although we provided suggestions for enterprise-wide digital solutions within the content to encourage staff to experiment with these, digital technologies were secondary to the primary focus of CloudFirst102 which was showcasing effective online teaching strategies.

We also invited the staff (learners) engaging with CloudFirst102 to share their personal experiences in embedded discussions that further contextualised the PD resource by incorporating the voices of colleagues. This also helped CloudFirst102 to be an active, dynamic and current resource rather than a series of static resources. The embedded discussions also served as a proxy for face-to-face corridor conversations. Such informal conversations have been shown to positively influence teaching practice as staff not only learn about new teaching and management strategies from their colleagues, but they also offer reassurance to more novice teachers (Thomson \& Trigwell, 2018).

We used the trimester journey as a narrative tool to bring structure and order to the resources because of the timedependent nature of some online teaching strategies, for example the importance of setting expectations and establishing a learning community early in the online learning environment (Stavredes, 2011; Sun \& Chen, 2016). It also allowed us to highlight that both staff and students need scaffolded support that will change over time as they become familiar with teaching and learning online.

\section{Input 4: institutional evidence (documents)}

And finally, we embedded the five principles of CloudFirst Learning Design (learning is scaffolded, learning is activity-focused, learning is feedback-focused, learning is social, and learning is supported), themselves drawn 
from research evidence, into CloudFirst102, so that together, these four inputs formed the evidence-based framework for the structure and selection of content in CloudFirst102 that is illustrated in Figures 1 and 2.

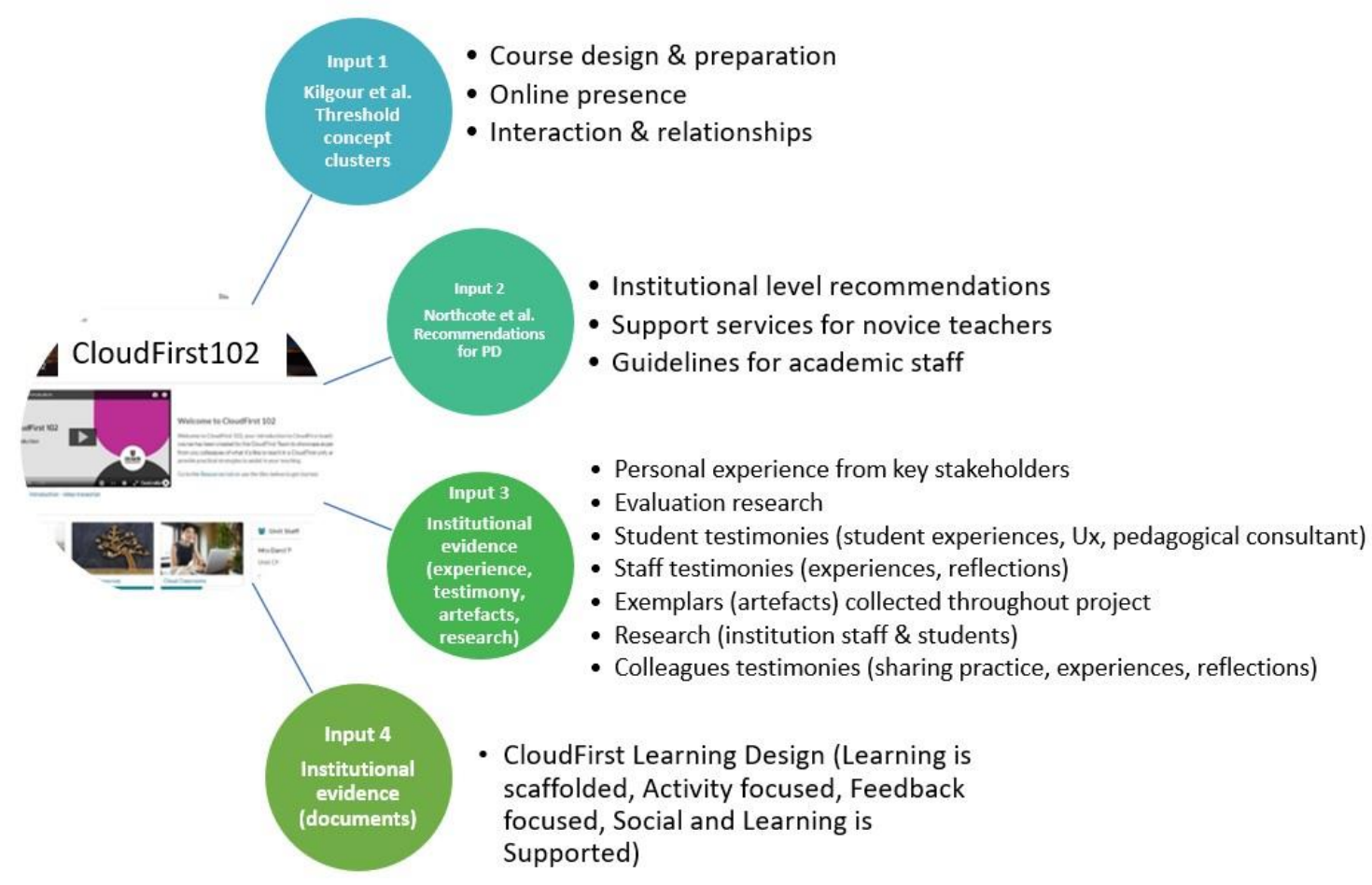

Figure 1: Evidence-based framework that guided the development of CloudFirst102
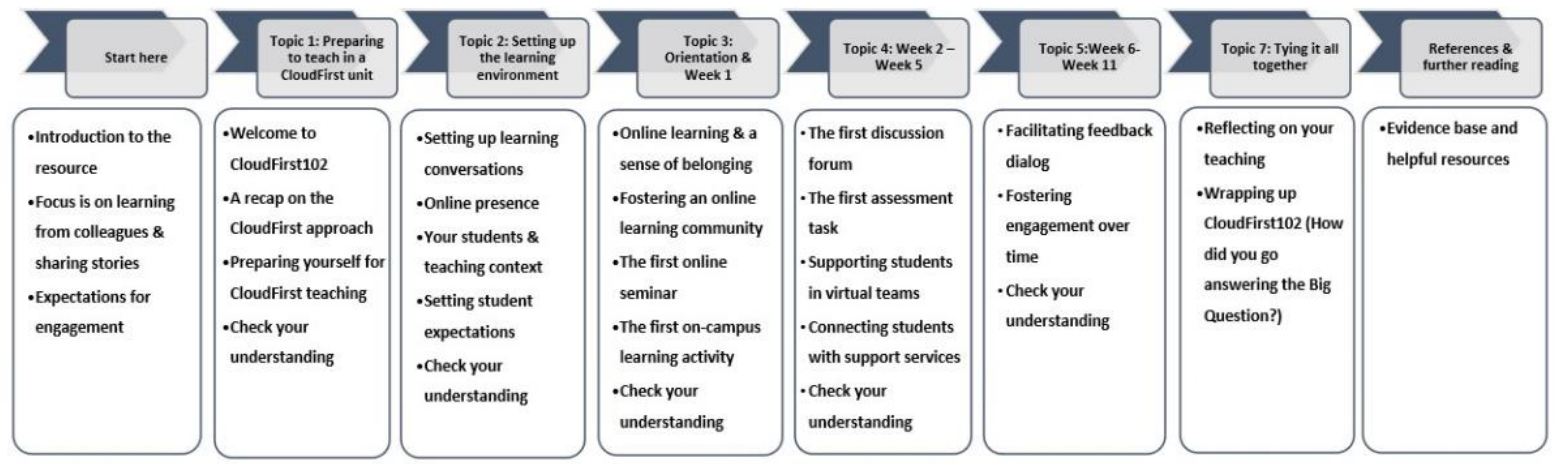

Figure 2: The content of CloudFirst102 was structured around a trimester journey

\section{Implementation of CloudFirst102}

CloudFirst102 was launched in April 2020, and while both CloudFirst101 and CloudFirst102 were designed to support a planned 'premium' approach to curriculum redesign and transition to online teaching, when the COVID19 restrictions prohibited on-campus teaching, we recognised an urgent need for 'practical' support for all teaching staff to rapidly transition to online teaching.

As CloudFirst101/102 were structured around threshold concepts related to teaching online, we were able to identify particular areas that staff may be challenged by when rapidly transitioning online, and design a series of synchronous 'DIY Lockdown Edition' workshops around these threshold concepts that complemented the content within CloudFirst101/102. In order to balance the 'practical' and the 'premium', and tailor the PD to the local educational context, we applied a set of guiding principles to our work that recognised the COVID-19 situation. These principles were: be kind to yourself and students; do what is realistic; 'DIY' doesn't mean staff aren't supported - there are teaching and learning support teams; think about a consistent student experience; and sustainability - think about what will happen when you return to campus. 
In the workshops we guided staff to scale-back the 'premium' to that which could be 'practically' achieved in preparation for the next trimester. As staff were drawing on resources in CloudFirst101/102 that were evidencebased, we were able to guide them towards good practice rather than 'panic-gogy' (Kamenetz, 2020; Morris, 2020), and target skill development to high impact online teaching strategies that support student success, for instance, developing social presence, fostering connection via synchronous seminars and facilitated discussion boards (Stone \& Springer, 2019), and setting clear expectations for student engagement (Stavredes, 2011).

\section{Preliminary conclusion}

Design decisions regarding the content and structure of PD for teachers transitioning online are complex and are often not evidence-based. This paper provides an example of how we utilised research evidence in combination with various forms of evidence drawn from the institution (personal experience, testimony, artefacts and documents), to create an evidence-based framework that guided our decision making when designing CloudFirst102. Anecdotally CloudFirst101 and CloudFirst102, and the DIY Lockdown Edition workshops have been well received by staff, and we are currently gathering feedback from staff on how these PD resources have assisted with their transition to teaching online. We hope that our example assists those designing PD for online teaching by identifying what forms of institutional-evidence can be combined with research-evidence to provide an evidence-based framework for PD design decisions.

NB. *'we' refers to the project team. The authors would like to acknowledge the work of the project team and our colleagues from across the university in the creation of CloudFirst102.

\section{References}

Deakin University. (2020). Deakin University 2019 Annual Report. Retrieved from https://www.deakin.edu.au/about-deakin/strategic-direction

Elliott, J. \& Taylor, D. (2019). “Okay, but what does it look like?” Building staff capacity in online learning design through role modelling. In Y.W. Chew, K. M. Chan, and A. Alphonso (Eds.), Personalised Learning. Diverse Goals. One Heart. ASCILITE 2019 Singapore (pp.413-417).

Kamenetz, A. (2020). 'Panic-gogy': Teaching online classes during the Coronavirus pandemic '[Blog post]'.

Retrieved from https://www.npr.org/2020/03/19/817885991/panic-gogy-teaching-online-classes- during-thecoronavirus-pandemic

Kilgour, P., Reynaud, D., Northcote, M., McLoughlin, C., \& Gosselin, K. P. (2019). Threshold concepts about online pedagogy for novice online teachers in higher education. Higher Education Research \& Development, 38(7), 1417-1431. doi: 10.1080/07294360.2018.1450360

McLoughlin, C. (2000). Creating partnerships for generative learning and systemic change: Redefining academic roles and relationships in support of learning. International Journal for Academic Development, 5(2), $116-128$. doi: 10.1080/13601440050200725

Meyer, J. H. F., \& Land, R. (2005). Threshold concepts and troublesome knowledge 2 -Epistemological considerations and a conceptual framework for teaching and learning. Higher Education, 49, 373-388. doi: 10.1007/s10734-004-6779-5

Northcote, M., Kilgour, P., Reynaud, D., Gosselin, K. P., \& McLoughlin, C. (2019). A Professional Learning Program for Novice Online Teachers Using Threshold Concepts. Online Learning, 23(4), 336-353. doi: 10.24059/olj.v23i4.1573

Osika, E. (2006). The concentric support model: a model for the planning and evaluation of distance learning programs. Online Journal of Distance Learning Administration, 9(3).

Stavredes, T. (2011). Effective Online Teaching: Foundations and Strategies for Student Success. Hoboken, United States: John Wiley \& Sons, Incorporated.

Stone, C., \& Springer, M. (2019). Interactivity, connectedness and 'teacher-presence': Engaging and retaining students online. Australian Journal of Adult Learning, 59(2), 146-169.

Sun, A., \& Chen, X. (2016). Online education and its effective practice: A research review. Journal of Information Technology Education: Research, 15, 157-190.

Thomas, G. (2004). Introduction: Evidence and practice. In R. Pring \& G. Thomas (Eds.), Evidence-based practice in education. (pp. 1-18): McCraw-Hill Education.

Thompson, K.E., \& Trigwell, K.R. (2018). The role of informal conversations in developing university teaching?, Studies in Higher Education, 43:9, 1536-1547, doi: 10.1080/03075079.2016.1265498 
Taylor, D. \& Elliot, J. (2020). Supporting the transition to online teaching through evidence-based professional development. In S. Gregory, S. Warburton, \& M. Parkes (Eds.), ASCILITE's First Virtual Conference. Proceedings ASCILITE 2020 in Armidale (pp. 1-6). https://doi.org/10.14742/ascilite2020.0113

Note: All published papers are refereed, having undergone a double-blind peer-review process.

The author(s) assign a Creative Commons by attribution licence enabling others to distribute, remix, tweak, and build upon their work, even commercially, as long as credit is given to the author(s) for the original creation.

(C) Taylor, D. \& Elliot, J. 2020 